\title{
Physical characteristics of West African dwarf goat as influenced by post-mortem processing methods
}

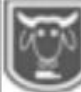

Okoh, P. I.

Department of Animal Science, Faculty of Agriculture

Ambrose Alli University, Ekpoma, Edo State

Abstract

Corresponding author: paulokoh75@gmail.com: 08030513292

A study on the physical characteristics of buck West African dwarf(WAD) goat as influenced by post-mortem processing methods was carried out. Nine WAD (bucks) with an average weight of $18.00 \pm 0.65 \mathrm{Kg}$ were allotted to three post-mortem processing methods, viz: singeing, scalding and skinning, as treatments; in three replicates. The experimental model was the completely randomized design. Parameters measured were, carcass weights and measurements, primal or wholesale cuts, as well as temperature and $\mathrm{pH}$ of carcass. The results showed that singeing significantly $(P<0.05)$ increased intact carcass weight from 5.64 $\mathrm{Kg}$ and $6.47 \mathrm{Kg}$ recorded in the skinned and scalded carcasses to $6.48 \mathrm{Kg}$, and relative weight from $3.97 \mathrm{Kg}$ recorded in both the skinned and scalded carcasses to $4.67 \mathrm{Kg}$. Length of carcass was significantly $(P<0.05)$ higher in the scalded carcass $(36.67 \mathrm{Kg})$ compared to the skinned and singed carcasses which recorded 30.67 and $28.67 \mathrm{Kg}$ respectively. While, skinning recorded a significant $(P<0.05)$ higher weight for depth of chest and maximum width of leg, having 17.67 and $13.67 \mathrm{~cm}$ compared to singeing and scalding having $16.67 \mathrm{~cm}$ each for depth of chest, 11.67 and $10.67 \mathrm{~cm}$ respectively for maximum width of leg. Also, primal cuts yield of rack, neck, shoulder and shank were significantly $(P<0.05)$ higher in singeing, while those of loin and leg were significantly $(P<0.05)$ higher in skinning. Scalding recorded the least yields in all the primal parts measured. The study further revealed that temperature fall was significantly $(P<0.05)$ higher in singeing, followed by scalding and least in skinning, as post-mortem time progressed from $0-60$ mins. While, fall in $\mathrm{pH}$ was also significantly $(P<0.05)$ higher in singeing, followed by skinning and least in scalding, as postmortem time progressed from $0-60$ mins. By this result, singeing as a processing method should be adopted by meat processors and home consumers, as it recorded higher carcass weights and primal cuts among other post-mortem processing methods.

\section{Keywords: Singeing, Scalding, Skinning, Physical characteristics, WAD goats.}

\section{Introduction}

The domestic goat (Capra spp.) is one of the oldest domesticated species of livestock and has been used for their milk, meat and skins etc. There are over three hundred distinct breeds of goats but the West African dwarf (WAD) goat is the commonest and most important indigenous breed in West and Central Africa (Omoruyi et al., 1991). Important attributes of the WAD goat include: excellent adaptation to its native habitat, high fertility and prolificacy, resistance to trypanosomiasis and gastrointestinal nematodes (Porter and
Mason, 2002), and can survive under stressful environment, poor nutrition and high temperature. The WAD goat is the most prolific of all the domesticated ruminants under sub-tropical conditions, possessing high frequency of kidding. It can handle very coarse fibrous and aromatic feeds and can survive under conditions inimical to other ruminant stocks (Osakwe, 2004).

These attributes have established the goat meat as a lean meat with favourable nutritional qualities; low in calories, total fat, saturated fat and lesser cholesterol, 
accounting for approximately $63 \%$ of all red meat consumed worldwide (Lewandoski, 2003). These attributes are in concordance with the present day consumer's demand for leaner and nutritious meat, and thus could be a basis for promoting the meat.

In assessing the carcass characteristics of the WAD goat, different methods could be employed. Paramount among these methods is the post-mortem processing (dehairing) method for animal carcasses known to affect its carcass characteristics, which include singeing, scalding and skinning (Omojola and Adesehinwa, 2006). Singeing is a method employed to burn off the hair of an animal, given the carcass skin a golden brown colour and an enhanced smoky flavour on the processed meat (Okubanjo, 1997). Scalding is a method of floating carcass or dipping of well bled animal in hot water to loosen the skin follicles in order to ease its removal (Monin et al., 1995). While, Skinning or convectional dressing according to Awosanya and Okubanjo (1993) is a simple act of pulling the subcutaneous skin, thereby removing some subcutaneous fat and exposing the internal carcass body. These post-mortem processing (dehairing) methods will not only affect the temperature and ultimate $\mathrm{pH}$ of carcass and its rate of decline but will also affect other carcass characteristics.

Several authors have reported on carcass characteristics subjected to these different post-mortem processing (dehairing) methods. Monin et al. (1995) reported on effects of dehairing Pigs by scalding or singeing, where carcass weights and yields were noticeably higher after singeing than after scalding. Okubanjo (1997) observed similar results for the chevon carcasses where dehairing by singeing resulted in markedly heavier carcass than after convectional dressing with lesser carcass weights. Also, Monin et al. (1995) reported a non-significant difference in temperature and $\mathrm{pH}$ between scalding and singeing dehairirng methods for the pigs. The lack of effect of the dehairing treatments on muscle temperature was in agreement with the observation of Vander Wal et al. (1993), that scalding at $60^{\circ} \mathrm{C}$ for as long as 12 minutes does not affect muscle temperature at a $5 \mathrm{~cm}$ depth. An increase in the percentage yield of leg in singed carcass and a decrease in loin, breast, shank and flank (BSF) was also reported by Okubanjo, (1997), when compared with those of the conventionally dressed carcasses. Thus, singeing of prerigour chevon carcasses have remarkable effects on the yield and physical characteristics of the carcass, and imposes a toughening effect on most of the carcass muscles Okubanjo (1997). This he said may be disadvantageous if tender meats are desired.

These post-mortem processing methods though applied to different livestocks including the chevon, but information on the WAD goat is scares. This study therefore seeks to provide information on physical characteristics of WAD goats (buck) as influenced by post-mortem processing methods.

\section{Materials and methods Experimental materials}

Nine WAD bucks of $18 \pm 0.65 \mathrm{Kg}$ live weight and approximately 1 year old were purchased from the open market in Ekpoma and transported to the Livestock Unit of the Teaching and Research Farm, Faculty of Agriculture, Ambrose Alli University, Ekpoma. They were fasted for 16 hours but had access to clean water.

\section{Processing (dehairing) method}

The animals were slaughtered in batches of three (3), randomly allotted to each of the post-mortem processing methods namely: singeing, scalding and skinning, with each 
method representing a treatment.

Singeing: In this method, the hairs of goat were flamed off and scrapped using a metal scrapper on the fire, following the procedures of Okubanjo (1997). Scalding: Here, the bled goats were dipped in hot water of $85^{\circ} \mathrm{C}$ for 30 seconds, after which the hairs were scrapped off with mental scrapper and knife, as described by Monin et al. (1995). Skinning: In skinning, a ring was made round one of the hind legs with a scalpel, which was inserted under the skin of the leg, to open it up to the root of the tail. The same was repeated with the other leg. While from the pelvic region, another incision was made up to the neck region. The hair was then pulled along the skin, thereby exposing the internal carcass, according to the procedures of Omojola and
Adesehinwa (2006).

\section{Carcass evaluation}

Evaluation and measurements of carcass were carried out as follows;

Preliminary weight measurements which include live weight, fasted, bled, carcass weights and dressing percentage, were measured using the hanging scale. Also, carcass weights and measurements which include intact carcass weight, eviscerated and relative carcass weights, as well as length of carcass, depth of chest, length of leg and maximum width of leg, were measured using a table scale and meter rule. Primal or wholesale cuts which include breast, back, neck, flank, loin, leg, shoulder and shank, were weighed with the aid of a table scale. Internal temperature and $\mathrm{pH}$ measurements were taken using the sensitive thermometer and $\mathrm{pH}$ scale.

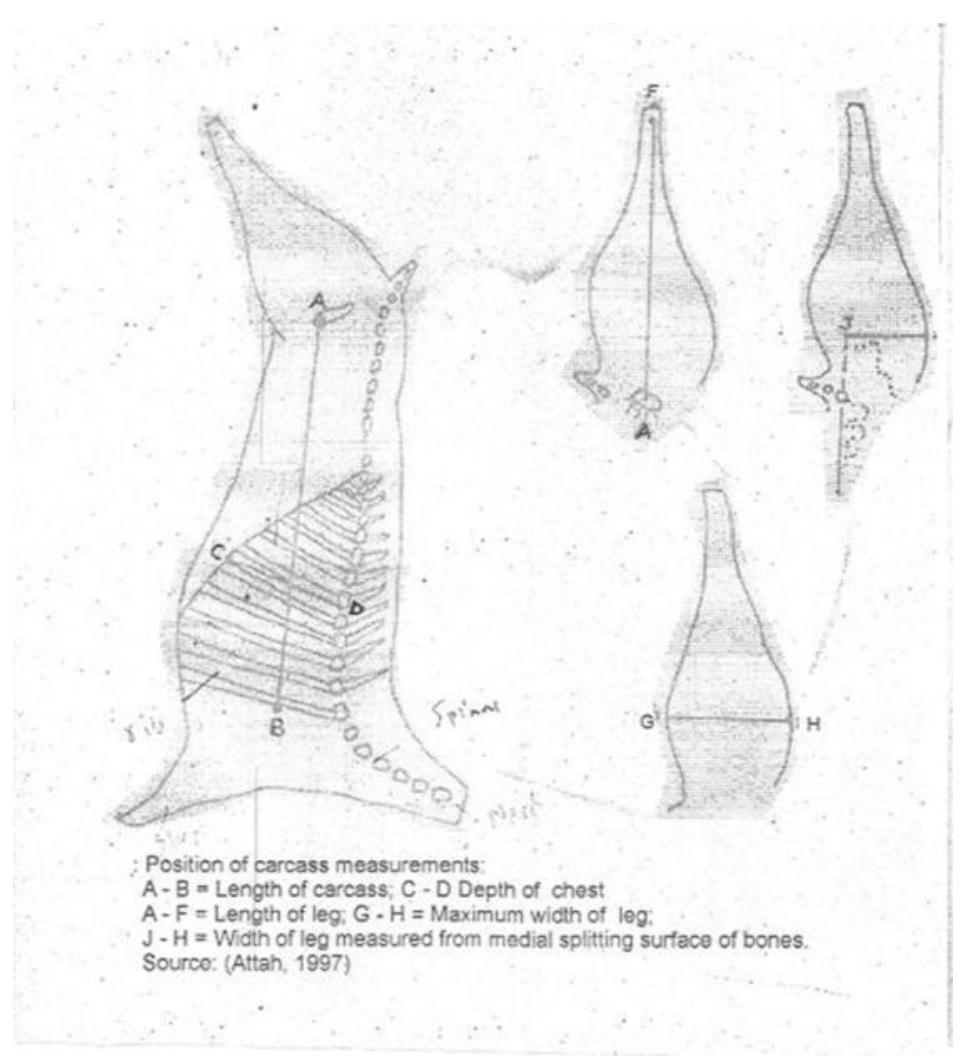

Fig.1: procedures for carcass measurements 


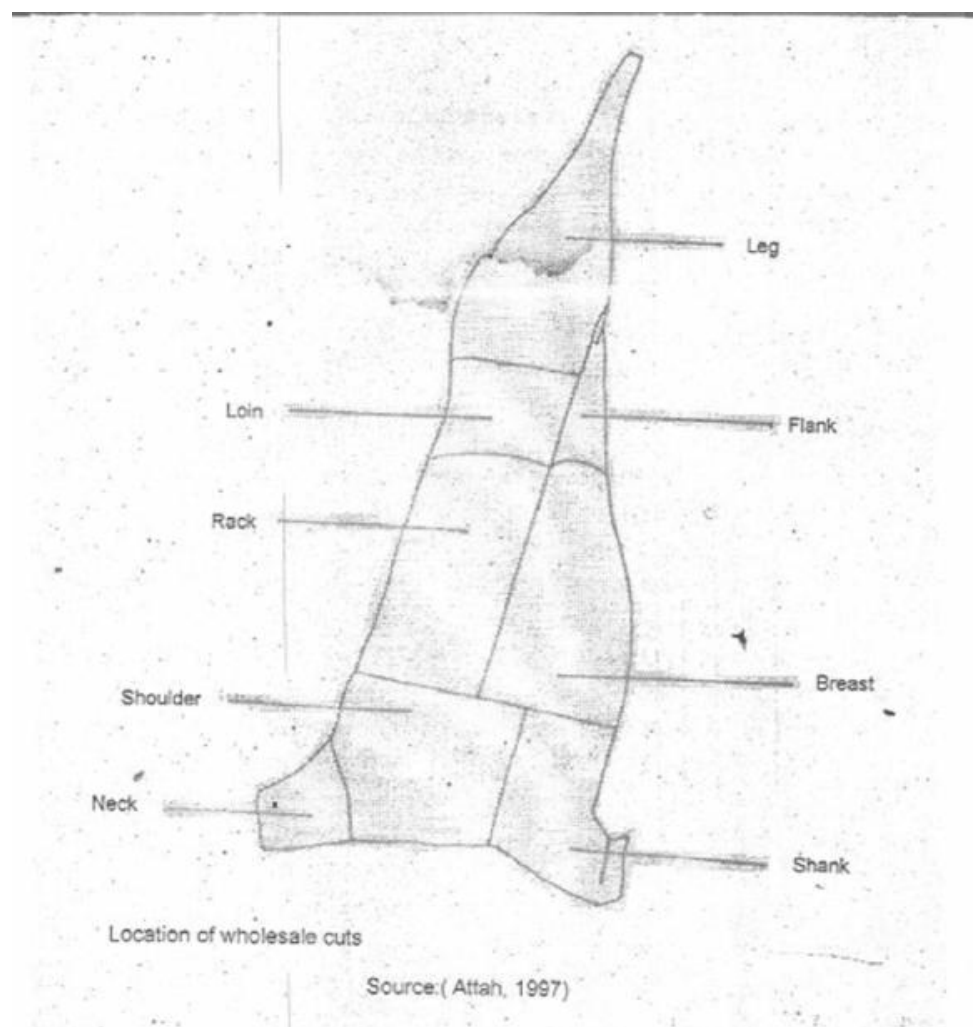

Fig. 2: Location of wholesale or primal cuts

\section{Experimentaldesign}

The design for the experiment was the completely randomized design, one way analysis of variance.

\section{Statistical analysis}

Results from the experiment were analyzed using analysis of variance, and means that showed significance were separated appropriately by the procedure of Statistical Analysis System (SAS), (2010).

\section{Results and discussions}

Results from the study are presented on each Table and discussions made accordingly, on each parameter measured below.

Table 1: Preliminary mean weights of West African dwarf goats

\section{Parameters}

Live Weight $(\mathrm{Kg})$

Fasted Weight $(\mathrm{Kg})$

Bled Weight $(\mathrm{Kg})$

Carcass Weight $(\mathrm{Kg})$

Dressing Percentage (\%)

weights

\section{1}

8.3

8.1

6.4

70.3
The results from Table (1) revealed a mean live weight of $9.1 \mathrm{Kg}$, fasted weight of $8.3 \mathrm{Kg}$, bled weight of $8.1 \mathrm{Kg}$, carcass weight of $6.4 \mathrm{Kg}$ and a dressing percentage of $70.3 \%$. These weights were relatively smaller compared with the findings of
Okoh (2006) for the Red Sokoto goats which had a mean live weight of $18 \mathrm{Kg}$, fasted weight of $16.75 \mathrm{Kg}$, bled weight of $16.00 \mathrm{Kg}$, dressed carcass weight of $10.00 \mathrm{Kg}$ and a dressing percent carcass of $55.56 \%$. Also, comparing carcass 
Okoh

characteristics of both breeds at different weights, Attah et al. (2004) reported that all body length and carcass measurements that had to do with height and length of animals were significantly $(\mathrm{P}<0.05)$ higher in Red Sokoto than in West African dwarf goats.

Table 2: Mean values of carcass weights and measurements as influenced by post-mortem processing methods

\begin{tabular}{lcccc}
\hline \multicolumn{1}{c}{ Parameters } & Scalding & Singeing & Skinning & SEM \pm \\
\hline Intact Carcass Weight (Kg) & $6.47^{\mathrm{a}}$ & $6.48^{\mathrm{a}}$ & $5.64^{\mathrm{b}}$ & 0.241 \\
Eviscerated weight (Kg) & 3.67 & 3.84 & 3.64 & 0.741 \\
Relative weight (Kg) & $3.97^{\mathrm{b}}$ & $4.69^{\mathrm{a}}$ & $3.97^{\mathrm{b}}$ & 0.377 \\
Length of Carcass (cm) & $36.67^{\mathrm{a}}$ & $28.67^{\mathrm{c}}$ & $30.67^{\mathrm{b}}$ & 2.267 \\
Length of Leg (cm) & 20.67 & 19.67 & 20.67 & 1.511 \\
Depth of Chest (cm) & $16.67^{\mathrm{b}}$ & $16.67^{\mathrm{b}}$ & $17.67^{\mathrm{a}}$ & 1.309 \\
Maximum Width of Leg (cm) & $10.67^{\mathrm{c}}$ & $11.67^{\mathrm{b}}$ & $13.67^{\mathrm{a}}$ & 1.309 \\
\hline
\end{tabular}

abc: Means of similar superscripts along rows are not significantly $(\mathbf{P}>0.05)$ different SEM= standard error of means

The results of the mean values of carcass weights and measurements as influenced by post-mortem processing methods showed that singeing significantly $(\mathrm{P}<0.05)$ elevated the intact carcass weight to 6.84 $\mathrm{Kg}$, as against skinning which weighed $5.64 \mathrm{Kg}$, and scalding had $6.47 \mathrm{Kg}$. This was as a result of the processing methods applied, as heat tends to swell or increase carcass weight, while skinning reduced it. It could also be as result of the Live Weight of the animal.

Eviscerated weight was not influenced by the post-mortem processing methods, though singeing recorded a higher value of $3.84 \mathrm{Kg}$ compared to scalding and skinning with 3.67 and $3.64 \mathrm{Kg}$ respectively. The values recorded here were almost similar, hence did not differ $(\mathrm{P}>0.05)$ significantly. Relative weight of carcass was significantly $(\mathrm{P}<0.05)$ influenced by post-mortem processing methods, with singeing recording a higher value of $4.69 \mathrm{Kg}$ compared with scalding and skinning having $3.97 \mathrm{Kg}$ both. This was as a result of the intact carcass weight which was initially higher in singeing.

Length of carcass was influenced by postmortem processing method applied, with a higher significant $(\mathrm{P}<0.05)$ value of $36.67 \mathrm{~cm}$ recorded for scalding as against singeing and skinning which had 28.67 and $30.67 \mathrm{~cm}$ respectively. This could be attributed to the processing method applied, since carcass when subjected to hot water increases in size. This result contradicts the findings of Okoh et al. (2016), where skinning significantly $(\mathrm{P}<0.05)$ elevated the carcass length of Red Sokoto goat compared to singeing and scalding.

Length of leg was not affected $(\mathrm{P}>0.05)$ by the post-mortem processing method applied, though scalding and skinning recorded higher values of $20.67 \mathrm{~cm}$ each, while singeing had $19.67 \mathrm{~cm}$. Here, values recorded for their Length were almost similar. Depth of chest showed a significant $(\mathrm{P}<0.05)$ difference among the processing methods applied, with skinning having a higher value of $17.67 \mathrm{~cm}$, as against scalding and singeing which had $16.67 \mathrm{~cm}$ each. The higher significance $(\mathrm{P}<0.05)$ recorded by the skinning processing method could be attributable to differences in the sizes of the carcass measured which could be higher in the skinned carcass. This result contradicts the report of Okoh et al., (2016), where scalding significantly 
$(\mathrm{P}<0.05)$ increased the depth of chest of Red Sokoto goat, as against singeing and skinning, which was attributed to the added weight and protective effects of the skin which was retained on the carcass as a result of the dressing method applied. Maximum width of leg was significantly $(\mathrm{P}<0.05)$ influenced by post-mortem processing methods, with skinning having higher value of $13.67 \mathrm{~cm}$, compared with scalding and singeing which had 10.67 and $11.67 \mathrm{~cm}$, respectively. This result was expected as result on Length of leg was initially higher in the skinned carcass.

Table 3: Mean values of primal cuts as influenced by post-mortem processing methods

\begin{tabular}{lcccc} 
Parameters & Scalding & Singeing & Skinning & SEM \pm \\
\\
\hline Breast $(\mathrm{Kg})$ & $0.20^{\mathrm{b}}$ & $0.30^{\mathrm{a}}$ & $0.30^{\mathrm{a}}$ & \\
Rack $(\mathrm{Kg})$ & $0.25^{\mathrm{c}}$ & $0.35^{\mathrm{a}}$ & $0.30^{\mathrm{b}}$ & 0.007 \\
Neck $(\mathrm{Kg})$ & $0.20^{\mathrm{c}}$ & $0.40^{\mathrm{a}}$ & $0.30^{\mathrm{b}}$ & 0.008 \\
Flank $(\mathrm{Kg})$ & $0.15^{\mathrm{b}}$ & $0.20^{\mathrm{a}}$ & $0.20^{\mathrm{a}}$ & 0.007 \\
Loin $(\mathrm{Kg})$ & $0.20^{\mathrm{c}}$ & $0.25^{\mathrm{b}}$ & $0.30^{\mathrm{a}}$ & 0.008 \\
Leg $(\mathrm{Kg})$ & $0.35^{\mathrm{c}}$ & $0.70^{\mathrm{b}}$ & $0.80^{\mathrm{a}}$ & 0.007 \\
Shoulder $(\mathrm{Kg})$ & $0.40^{\mathrm{c}}$ & $0.50^{\mathrm{a}}$ & $0.45^{\mathrm{b}}$ & 0.006 \\
Shank $(\mathrm{Kg})$ & $0.40^{\mathrm{b}}$ & $0.50^{\mathrm{a}}$ & $0.50^{\mathrm{a}}$ & 0.007
\end{tabular}

abc: Means of similar superscripts along rows are not significantly $(\mathrm{P}>0.05)$ different

SEM= standard error of means

The results of primal or wholesale cuts showed that singeing significantly $(\mathrm{P}<0.05)$ elevated the yields of almost all the cuts measured, though not significantly $(\mathrm{P}>0.05)$ different from skinning for the breast carcass, with both having a weight of $0.30 \mathrm{Kg}$. It also imposed a significantly $(\mathrm{P}<0.05)$ higher weight for rack and neck, having 0.35 and $0.40 \mathrm{Kg}$, compared to skinning and scalding, which had $0.30 \mathrm{Kg}$ each, and 0.25 and $0.20 \mathrm{Kg}$ for rack and neck respectively. Weight of flank was not significantly $(\mathrm{P}>0.05)$ different between singeing and skinning, with both having $0.20 \mathrm{Kg}$, but significantly different $(\mathrm{P}<0.05)$ from scalding which had $0.15 \mathrm{Kg}$. The higher weight in flank recorded in this study for the skinned carcass is in line with the findings of Okubanjo (1997), where yields of breast, shank and flank (BSF) significantly decreased $(\mathrm{P}<0.05)$ in singed carcass when compared with those of the conventionally skinned carcass.

Skinning imposed significantly $(\mathrm{P}<0.05)$ higher weights for loin and leg, having 0.30 and $0.80 \mathrm{Kg}$, compared with singeing and scalding which had 0.25 and $0.70 \mathrm{Kg} ; 0.20$ and $0.35 \mathrm{Kg}$ for lion and leg respectively. This result is in agreement with report of Okubanjo (1997), that yield of loin was significantly $(\mathrm{P}<0.05)$ higher in conventionally skinned carcass, but disagreed that the percent yield of leg significantly $(\mathrm{P}<0.05)$ increased in the singed carcass. Yield of shoulder was significantly $(\mathrm{P}<0.05)$ higher in singeing, having $0.50 \mathrm{Kg}$ compared with skinning and scalding which had 0.45 and $0.40 \mathrm{Kg}$ respectively. While, the weight of shank did not differ significantly $(\mathrm{P}>0.05)$ between singeing and skinning, with both having $0.50 \mathrm{Kg}$ each but differs significantly $(\mathrm{P}<0.05)$ from scalding which had $0.40 \mathrm{Kg}$. The high weight recorded in shank in this study for the skinned carcass is in line with the findings of Okubanjo (1997).

A significantly $(\mathrm{P}<0.05)$ higher and lower weights recorded for leg and flank 
respectively among other primal cuts in this study, were also observed by Attah (1997) for the Red Sokoto and West African Dwarf goats, and Okoh (2006) for the Red Sokoto goats. Differences in weights of these primal or wholesale cuts can be attributed to differences in sizes and shapes of the meat parts.

Table 4: Temperature $\left({ }^{0} \mathrm{C}\right)$ of intact carcass as influenced by post-mortem processing methods

\begin{tabular}{ccccc} 
Time (mins) & Scalding & Singeing & Skinning & SEM $\underline{ \pm}$ \\
\hline 0 & $40.73^{\mathrm{a}}$ & $41.33^{\mathrm{a}}$ & $35.47^{\mathrm{b}}$ & 2.63 \\
20 & $37.60^{\mathrm{b}}$ & $40.03^{\mathrm{a}}$ & $34.23^{\mathrm{c}}$ & 2.02 \\
40 & $34.00^{\mathrm{b}}$ & $38.80^{\mathrm{a}}$ & $32.53^{\mathrm{c}}$ & 1.52 \\
60 & $31.90^{\mathrm{b}}$ & $36.93^{\mathrm{a}}$ & $30.63^{\mathrm{c}}$ & 0.94 \\
\hline
\end{tabular}

abc: Means of similar superscripts along rows are not significantly $(P>0.05)$ different ; $\mathrm{SEM}=$ standard error of means.

The data on internal temperature of carcass taken at different times as influenced by post-mortem processing methods showed that singeing significantly $(\mathrm{P}<0.05)$ elevated the temperature of intact carcass at 0 mins from $35.47\left({ }^{\circ} \mathrm{C}\right)$ observed in the skinned carcass to $41.33\left({ }^{\circ} \mathrm{C}\right)$, which was not significantly $(\mathrm{P}>0.05)$ different from the scalded carcass. Singeing also increased the temperature of carcass significantly $(\mathrm{P}<0.05)$ at $20 \mathrm{mins}$ from 34.23 and $37.60\left({ }^{\circ} \mathrm{C}\right)$ observed in skinned and scalded carcasses to $40.03\left(0^{c}\right)$. This result followed a similar trend for time at 40 and 60 mins respectively. The fall in temperature as post-mortem time progresses, as observed in this study followed a similar trend reported by Omojola and Adesehinwa (2006) for the rabbit carcasses. The differences in temperature of the carcasses measured in this study can be attributed to the different intensities of heat of the different processing methods. Also, the gradual fall in temperature of the carcass was as a result of the cooling effect, which evened out as post-mortem time progressed. Based on this observation, Offer (1991) established that the muscle is metabolically active and generates heat during the pre-rigour period, mainly due to the conversion of glycogen to lactic acid and also due to the hydrolysis of creatine phosphate and adenosine triphoshate (ATP). Consequently, the constant elevated temperature during the first 30 mins can be considered as an effect of continued heat production as long as energy in the form of creatine phosphate and ATP were left, and that the subsequent temperature decline after 30 mins coincide with exhaustion of creatine phosphate (Gumilla et al, 2005). A graphical representation of the relationship between temperature and time post-mortem, shows that temperature decreases as post-mortem time increases.

The results on $\mathrm{pH}$ of carcasses measured at different times as influenced by postmortem processing methods showed that singeing significantly $(\mathrm{P}<0.05)$ increased the initial $\mathrm{pH}$ of carcass at 0 mins postmortem from 5.60 and 5.76 recorded in scalding and skinning respectively to 5.93 . Also, singeing significantly $(\mathrm{P}<0.05)$ elevated the $\mathrm{pH}$ at 20 mins post-mortem from 5.50 and 5.53 recorded in scalding and skinning to 5.80. At 40 mins post-mortem, $\mathrm{pH}$ values recorded for singeing and skinning (5.46 and 5.40) did not differ significantly $(\mathrm{P}>0.05)$, but differs 


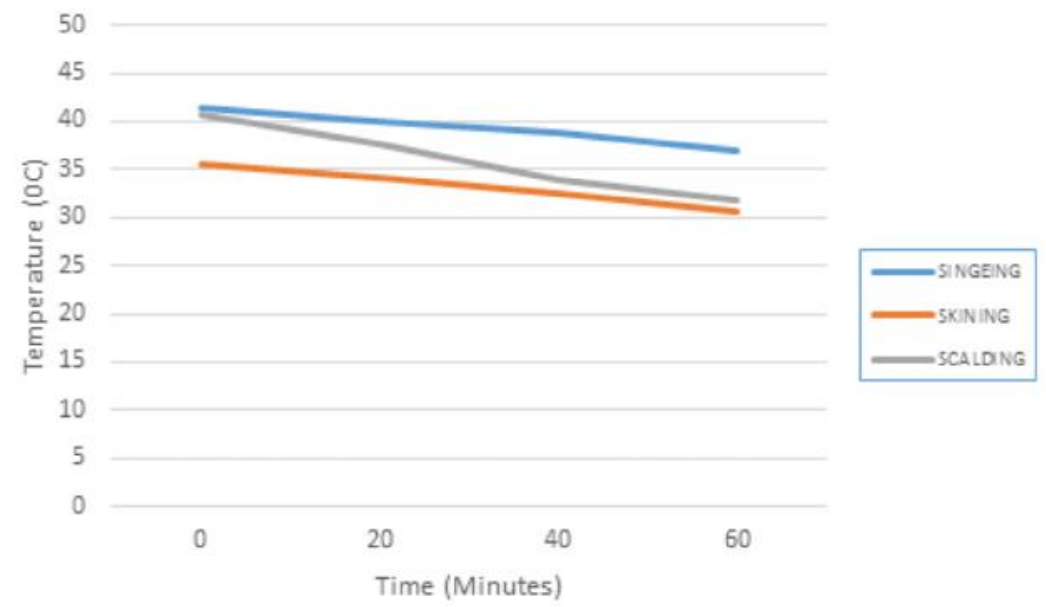

Changes in Temperature and Time as influenced by post-mortem processing methods

Table 5: Meat $\mathrm{pH}$ as influenced by post-mortem processing methods

\begin{tabular}{ccccc}
\hline Time (mins) & Scalding & Singeing & Skinning & SEM \pm \\
\hline 0 & $5.60^{\mathrm{c}}$ & $5.93^{\mathrm{a}}$ & $5.76^{\mathrm{b}}$ & 0.11 \\
20 & $5.50^{\mathrm{b}}$ & $5.80^{\mathrm{a}}$ & $5.53^{\mathrm{b}}$ & 0.08 \\
40 & $5.30^{\mathrm{b}}$ & $5.46^{\mathrm{a}}$ & $5.40^{\mathrm{ab}}$ & 0.06 \\
60 & 5.10 & 5.10 & 5.20 & 0.03 \\
\hline
\end{tabular}

abc: Means of similar superscripts along rows are not significantly $(\mathrm{P}>0.05)$ different ;

SEM= standard error of means.

significantly $(\mathrm{P}<0.05)$ from scalding (5.30). When at 60 mins post-mortem, there was no significant difference $(\mathrm{P}>0.05)$ between processing methods. The result revealed a gradual fall in $\mathrm{pH}$ values as postmortem time progresses. This observation also followed a similar trend reported by Omojola and Adesehinwa (2006) for the rabbit carcasses. The gradual fall in the $\mathrm{pH}$ values of the carcass from 0 mins postmortem observed in this study was as a result of rigour mortis action, where the circulatory system has stopped functioning (Ikeme, 1990). This led to the production of lactic acid by anaerobic metabolism which remains in the muscles and increases in concentration, thereby causing the lowering of $\mathrm{pH}$ in the carcass. Also, the increase in $\mathrm{pH}$ values of the singed compared to scalded and skinned carcasses as observed in this study followed a similar trend reported by Omojola and Adesehinwa (2006) for the rabbit carcasses. This they said could be attributed to the fission of protein chain at labile linkages involving ionidazole-SH and $\mathrm{OH}$ groups, followed by hydrogen bonding between carboxyl and amino group.

A graphical representation of the relationship between $\mathrm{pH}$ and time postmortem shows that $\mathrm{pH}$ also decreased as post-mortem time increased. 


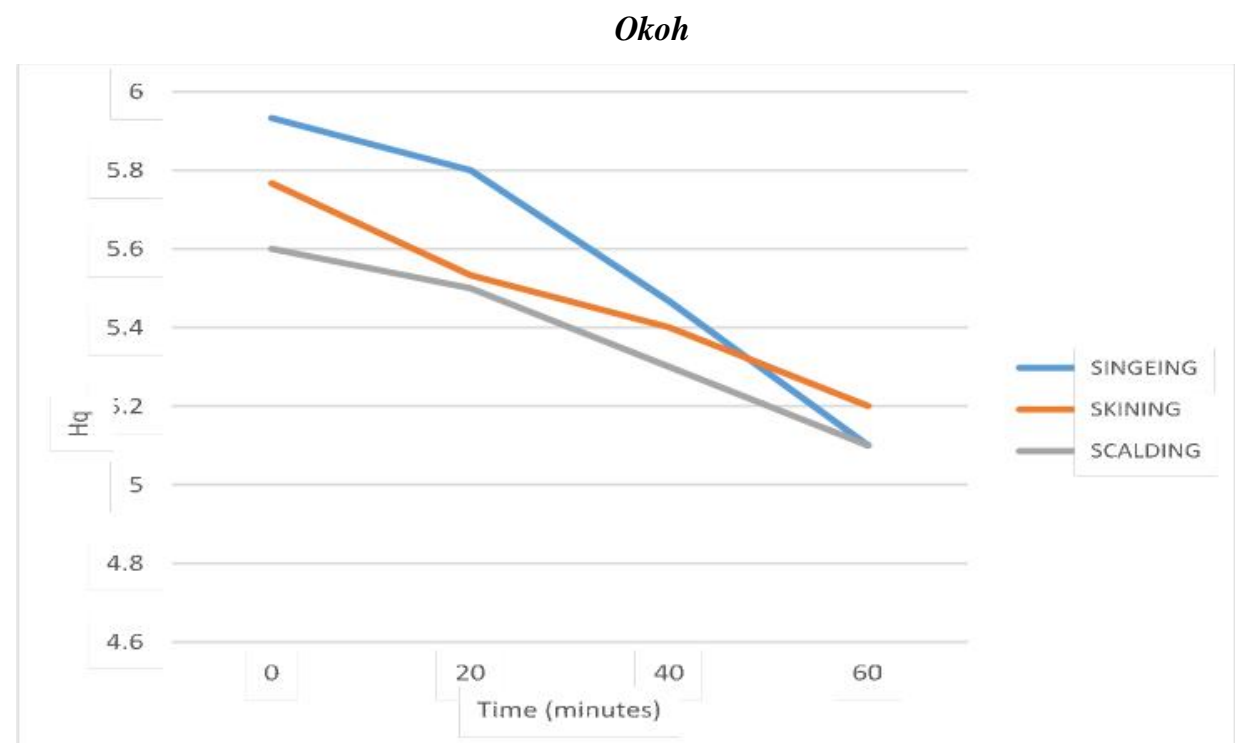

Changes in pH and Time as influenced by post-mortem processing methods

\section{Conclusion}

Based on the findings from this study, it can be said that post-mortem processing methods influenced to a large extent the physical characteristic of WAD goats, as Singeing imposed higher values in most parameters that have to do with weights. Scalding increased the length of carcasses but did not have any influence on yields of wholesale cuts of meat while, skinning elevated the depth of chest and maximum width of leg. Temperature and $\mathrm{pH}$ fall were also affected by post-mortem process methods, which was higher in the Singed carcass, followed by the Scalded and less in the Skinned carcass, as post-mortem time progressed from 0-60 minutes.

It is therefore recommended that singeing processing method be adopted by meat processors and home consumers, since it recorded higher carcass weights and primal cuts among other post-mortem processing methods.

\section{References}

Attah, S. 1997. Live performance, carcass and offal characteristics of goat slaughtered at different weights.
Ph.D Thesis. Animal Science Department, University of Ibadan, Nigeria.

Attah, S., Okubanjo, A. O., Omojola, A. B. and Adesehinwa, A. O. K. 2004. Body and Carcass linear measurements of goats slaughtered at different weights. Livestock Research for Rural Department 16 (8) 2004.

Awosanya, B. and Okubanjo, A. O. 1993. Effect of skinning, scalding or singeing on the physical characteristics of rabbit carcasses. Nig. Food jour. 11: 147-148.

Gumilla, L., Henckla, P., Karlssomb, A. H. and Henrik, J. 2005. Significance of early post-mortem temperature and $\mathrm{pH}$ decline on colour characteristics of pork loin from different cross breeds. Meat Science (72): 613-623.

Ikeme, A. I. 1990. Meat Science and Technology. A Comprehensive Approach. $1^{\text {st }}$ ed. African-Feb Publisher Ltd, Nigeria.

Lewandowski, R. 2003. Goat: the other meat. Buckeye meat goat newsletter vol. 1. The Ohio State 
Physical characteristics of West African dwarf goat as influenced by post-mortem processing methods

University Extension. Retrieved July 18, 2008. of experimental trypanosomiasis. Tropical Agric. 82: $143-147$

Monin, G., Talmaut, A., Aillery, P. and Collars, G. 1995. Effect on carcass weight and meat quality of pigs dehaired by scalding or singeing post-mortem. Meat science 39: 247-254. Elseviere ltd.

Offer, G. 1991. Modeling of the formation of pale soft exudative meat effects of chilling regime and extent of glycolysis. Meat Science 30: 157184

Okoh, P. 2006. Physico-Chemical properties of Red Sokoto Buck goats as affected by singeing, scalding and skinning. MSc. Dissertation. Animal Science Department, University of Ibadan.

Okoh, P. I., Okoruwa, M. I. and Isidahomen, C. E. 2016. Carcass measurements and chemical composition of Red Sokoto goat (bucks) as influenced by dressing methods. Nigerian journal of agriculture andforestry (NJAF).

Okunbanjo, A. O. 1997. Meat Characteristics of singed and conventionally dressed Chevon carcasses. J. Food Sci. Techn. 34 (6): 494-497.
Omojola, A. B. and Adesehinwa, A. O. K. 2006. Meat characteristics of scalded, singed and conventionally dressed Rabbit carcasses. InterDigital Org. for scientific information. World Jour.2001.1(1)

Omoruyi, S. A., Orhue, U. X., Akerobo, A. A. and Aghimien, C. I. 1991. Prescribed Agricultural Science for senior secondary schools. $2^{\text {nd }}$ edition. Pp. 321-323.

Osakwe, I. I. 2004. Livestock nutrition: in effective techniques of livestock and fish farming. A tool for poverty alleviation. (Ogunji, J. and Osakwe, I.I). ESDU, Abakaliki. Pp.11.

Porter, V. and Mason, I. L. 2002. Mason's world dictionary of livestock breeds, types and varities. New York, C.A.B International.

SAS. 2010. The Statistical Analysis System for windows. SAS software, version 9.0 Cary NC, USA.

Vander Wal P. G., Van Beek, G., Veerkamp, C. H. and Wijngards, G. 1993. Meat Science. 34, 395402.

Received: $30^{\text {th }}$ November, 2017

Accepted: $3^{\text {rd }}$ March, 2018 